\title{
The Challenge of Integrating Radiotherapy in the Multimodal Treatment of Breast Cancer
}

\author{
Rainer Souchon ${ }^{\mathrm{a}} \quad$ Juergen Dunst $^{\mathrm{b}}$ \\ aMVZ Radioonkologie, Klinik für Radioonkologie, Universitätsklinikum Tübingen, \\ ${ }^{b}$ Klinik für Strahlentherapie, Universitätsklinikum Schleswig-Holstein, Lübeck, Germany
}

Radiotherapy is a local therapy modality and is integrated in a multimodal treatment concept. It is mandatory and standard in all patients with breast-preserving therapy and is also indicated in the majority of patients who undergo mastectomy. Adjuvant radiotherapy generally improves local tumor control and reduces the risk of a locoregional recurrence by a factor of 3-4 [1-3]. In patients with a high risk of local recurrence, improved local control is associated with improved survival [1, 3-8]. Antineoplastic adjuvant systemic therapy may contribute to local control and enhances the efficacy of radiotherapy but its effect alone is not sufficient to replace radiotherapy $[1,3,9]$.

In the past years, a variety of major changes in radiotherapy have been implemented in the treatment of breast cancer. This includes radiobiology (e.g., alternative fractionation regimens such as hypofractionation), target volume concepts (e.g., partial breast irradiation) and new techniques (e.g., intraoperative radiotherapy). All these developments have to be integrated in the complex multimodal treatment concepts in breast cancer and treatment should meet well-defined quality criteria [10]. The objective of the focus in this issue of BREAST CARE is to discuss some of the burning questions currently discussed in radiotherapy in the light of the actual data.

Dunst and Dellas [11] discuss the impact of margin status in breast-preserving therapy. There is no evidence that a specific margin width is required in patients undergoing radiotherapy. In particular, a benefit of re-resections after R0resection is questionable. On the other hand, efforts should be made to ensure optimal delivery of whole-breast and boost radiotherapy because of its significant impact on tumor control.

Offersen and coworkers [12], on behalf of the Radiotherapy Committee of the Danish Breast Cancer Group (DBCG), comment on long-term data of postmastectomy radiotherapy (PMRT) from the Danish DBCG trials 82b and 82c. These large trials included patients after mastectomy and axillary dissection with at least 8 nodes removed. Both trials provide evidence for a survival benefit by PMRT in patients with 1-3 positive nodes and have led to changes in international guidelines from avoidance of PMRT in this subgroup to now 'strongly consider' [13-17]. Moreover, new data from the Danish studies show no excess cardiac mortality despite the fact that the radiotherapy techniques in this period were not yet able to meet contemporary quality criteria. Therefore, cardiac risk due to radiation can be considered low if modern techniques are used.

Dellas [18] focuses on a new and highly interesting topic, namely the impact of local therapy on metastatic lesions in patients with a limited number of metastases; this state of disease with only few (not more than 3-4) detectable metastatic sites has been described as 'oligometastatic' disease. There is some evidence that these patients may have a better prognosis than other metastatic patients and that the progression of disease often arises from the initially visible metastases. Improving local control at metastatic sites may therefore impact on the further course of disease. Currently, local therapy to metastatic sites is administered only with the objective of palliation but the hypothesis for future studies is to test whether radiotherapy may have a curative potential in subgroups with (oligo-)metastatic disease.

Hermann and Nitsche [19] discuss the impact of axillary irradiation. They emphasize that interpretation of data requires differentiation of studies with regard to prognosis (node-negative vs. node-positive patients), surgical procedures (axillary clearance, sampling, sentinel-node biopsy, or nothing) and radiotherapy techniques (unavoidable partial irradiation of lymph nodes by breast radiotherapy vs. full axillary irradiation). Radiotherapy is clearly effective in reducing the risk for axillary recurrence and can be used as alternative or in addition to surgical procedures. Recent and yet early data suggest that lymph node irradiation may contribute to improved disease-free survival in certain subgroups of patients. The impact of radiotherapy is currently further investigated in a variety of ongoing studies.

\section{KARGER}

Fax +497614520714

Information@Karger.de

www.karger.com (c) 2011 S. Karger GmbH, Freiburg

1661-3791/11/0065-0345\$38.00/0

Accessible online at:

www.karger.com/brc
Prof. Dr. med. R. Souchon

MVZ Radioonkologie, Klinik für Radioonkologie

Universitätsklinikum Tübingen (UKT)

Hoppe-Seyler-Str. 3, 72076 Tübingen, Germany

Tel. +49 7071 29-82180, Fax -3639

rainer.souchon@med.uni-tuebingen.d 
Petersen and Würschmidt [20] outline how changes in techniques and understanding of the biology of normal tissue reactions to radiation have improved treatment safety. This holds true for local complications such as breast fibrosis, lymphedema or brachial plexopathy, but also for late risks, such as cardiac morbidity and mortality.

Breast cancer treatment is a challenge for a multidisciplinary team. This issue of BrEAST CARE hopefully helps to better understand the complex interactions between radiotherapy and other modalities in multimodal treatment concepts and opens minds for further improvement in the future.

\section{Disclosure Statement}

The authors declare that there are no conflicts of interest.

\section{References}

1 Clarke M, Collins R, Darby S, et al. for the Early Breast Cancer Trialists' Collaborative Group: Effects of radiotherapy and of differences in the extent of surgery for early breast cancer on local recurrence and 15-year survival: an overview of the randomised trials. Lancet 2005;366:2087-2106.

2 Darby S, on Behalf of the Early Breast Cancer Trialists' Collaborative Group University of $\mathrm{Ox}$ ford, GB: Overview of the randomised trials of radiotherapy in early breast cancer. SABCS 2009; Minisymposium 3,MS3-1.

3 Early Breast Cancer Trialists' Collaborative Group (EBCTCG), Darby S, McGale P, Correa C, Taylor C, Arriagada R, Clarke M, Cutter D, Davies C, Ewertz M, Godwin J, Gray R, Pierce L, Whelan T, Wang Y, Peto R: Effect of radiotherapy after breast-conserving surgery on 10-year recurrence and 15-year breast cancer mortality in woman with early breast cancer: analysis of individual patient data on 10,801 women in 17 randomised trials. Lancet 2011, submission in preparation.

$\checkmark 4$ Anderson SJ, Wapnir I, Dignam JJ, Fisher B, Mamounas EP, Jeong JH, Geyer CE Jr, Wickerham DL, Costantino JP, Wolmark N: Prognosis after ipsilateral breast tumor recurrence and locoregional recurrences in patients treated by breast-conserving therapy in five National Surgical Adjuvant Breast and Bowel Project protocols of node-negative breast cancer. J Clin Oncol 2009;27:2466-2473.

$\checkmark 5$ Mannino M, Yarnold JR: Local relapse rates are falling after breast conserving surgery and systemic therapy for early breast cancer: can radiotherapy ever be safely withheld? Radiother Oncol 2009;90:14-22.

6 Poortmans P: Evidence based radiation oncology: breast cancer. Radiother Oncol 2007;84:84-101.
7 Voordeckers M, Vinh-Hung V, Lamote J, Bretz A, Storme G: Survival benefit with radiation therapy in node-positive breast carcinoma patients. Strahlenther Onkol 2009;185:656-662.

8 Weaver DL, Ashikaga T, Krag DN, Skelly JM, Anderson SJ, Harlow SP, Julian TB, Mamounas EP, Wolmark N: Effect of occult metastases on survival in node-negative breast cancer. N Engl J Med 2011;364:412-421.

-9 Pötter R, Gnant M, Kwasny W, Tausch C, Handl-Zeller L, Pakisch B, Taucher S, Hammer J, Luschin-Ebengreuth G, Schmid M, Sedlmayer F, Stierer M, Reiner G, Kapp K, Hofbauer F, Rottenfusser A, Pöstlberger S, Haider K, Draxler W, Jakesz R; Austrian Breast and Colorectal Cancer Study Group: Lumpectomy plus tamoxifen or anastrozole with or without whole breast irradiation in women with favorable early breast cancer. Int J Radiat Oncol Biol Phys 2007;68:334-340.

10 Brucker SY, Wallwiener M, Kreienberg R, Jonat W, Beckmann MW, Bamberg M, Wallwiener D, Souchon R: Optimizing the quality of breast cancer care at certified German breast centers: a benchmarking analysis for 2003-2009 with a particular focus on the interdisciplinary specialty of radiation oncology. Strahlenther Onkol 2011;187:89-99.

11 Dunst J, Dellas K: Margins! Margins. Margins? How important is margin status in breast conserving therapy? Breast Care 2011;6: DOI: $10.1159 / 000333145$.

12 Offersen B, Brodersen HJ, Moeller Nielsen M, Overgaard J, Overgaard M on behalf of the DBCG Radiotherapy Committee: Should postmastectomy radiotherapy to the chest wall and regional lymph nodes be standard for patients with 1-3 positive lymph nodes? Breast Care 2011;6: DOI: 10.1159/000333250.
13 Belkacémi Y, Fourquet A, Cutuli B, Bourgier C, Hery M, Ganem G, Marsiglia H, Namer M Gligorov J, Azria D: Radiotherapy for invasive breast cancer: guidelines for clinical practice from the French expert review board of Nice/Saint-Paul de Vence. Crit Rev Oncol Hematol 2010;79:91-102.

14 Cardoso F, Stordeur S, Vlayen J, Bourgain C, Carly B, Christiaens MR, Cocquyt V, Lifrange E, Neven P, Scalliet P, Schobbens JC, Van Goethem M, Villeirs G: Scientific support of the College of Oncology: update of the national guidelines on breast cancer. Good Clinical Practice (GCP). Brussels. Belgian Health Care Knowledge Centre (KCE). 2010. KCE Reports 143C. D/2010/ $10.273 / 77$.

15 National Institute for Health and Clinical Excellence (NICE): Early and Locally Advanced Breast Cancer: Diagnosis and Treatment. (Clinical Guideline 80.) London, NICE, 2009. www.nice.org.uk/ CG80

16 National Comprehensive Cancer Network (NCCN): Clinical Practice Guidelines in Oncology: Breast Cancer - version V.2,2011. www.nccn.org/ professionals/physician_gls/PDF/breast.pdf

17 New Zealand Guidelines Group: Management of Early Breast Cancer. Wellington, New Zealand Guidelines Group, 2009; www.nzgg.org.nz

18 Dellas K: Has radiotherapy a curative potential in metastatic patients? The concept of local therapy in oligometastatic breast cancer. Breast Care 2011;6: DOI: 10.1159/000333115.

19 Hermann R, Nitsche M: Axillary irradiation as an imperative alternative to axillary dissection in clinically lymph node-negative but sentinel nodepositive breast cancer patients? Breast Care 2011;6: DOI: $10.1159 / 000333835$

20 Petersen C, Würschmidt F: Late toxicity of radiotherapy: a problem or a challenge for the radiation oncologist? Breast Care 2011;6: DOI: $\underline{10.1159 /}$ 000334220 . 